\title{
Integrating an automated activity monitor into an artificial insemination program and the associated risk factors affecting reproductive performance of dairy cows
}

\author{
Tracy A. Burnett, ${ }^{*}$ Augusto M. L. Madureira, ${ }^{*}$ Bruna F. Silper, ${ }^{*}$ A. C. C. Fernandes, ${ }^{*} \dagger$ and Ronaldo L. A. Cerri ${ }^{* 1}$ \\ *Applied Animal Biology, Faculty of Land and Food Systems, University of British Columbia, Vancouver, Canada V6T $1 Z 4$ \\ †Federal Rural University of Pernambuco, Department of Veterinary Medicine, Recife, Brazil 52171-900
}

\begin{abstract}
The aim of this study was to compare 2 reproductive programs for the management of first postpartum artificial insemination (AI) based on activity monitors and timed AI, as well as to determine the effect of health-related factors on detection and expression of estrus. Lactating Holstein cows $(\mathrm{n}=918)$ from 2 commercial farms were enrolled. Estrous cycles of all cows were presynchronized with 2 injections of $\mathrm{PGF}_{2 \alpha}$ administered 2 wk apart. Treatments were (1) first insemination performed by timed AI (TAI) and (2) first insemination based upon the detection of estrus by activity monitors (ACT; Heatime, SCR Engineering, Netanya, Israel) after the presynchronization, whereas cows not inseminated by the detection of estrus were enrolled in the Ovsynch protocol. Body condition score (BCS; scale 1 to 5), hock score (scale: 1 to 4), gait score (scale: 1 to 4), and corpus luteum presence detected by ovarian ultrasonography were recorded twice during the presynchronization. On the ACT treatment, $50.5 \%$ of cows were inseminated based on detected estrus, whereas $83.2 \%$ of the cows on the TAI treatment were inseminated appropriately after the timed AI protocol. Pregnancy per AI did not differ by treatment (30.8 vs. $33.5 \%$ for ACT and TAI, respectively). Success of pregnancy was affected by parity, cyclicity, BCS, milk production, and a tendency for leg health. In addition, treatment $\times$ cyclicity and treatment $\times$ parity interactions were found to affect pregnancy success, where anovulatory cows and older cows had compromised pregnancy outcomes on the ACT treatment but not on the TAI treatment. Factors affecting pregnancy outcomes varied among farms. Hazard of pregnancy by 300 DIM was affected by farm, parity, BCS, a treatment $\times$ cyclicity interaction, and a tendency for an interac-
\end{abstract}

Received November 2, 2016.

Accepted February 21, 2017.

${ }^{1}$ Corresponding author: ronaldo.cerri@ubc.ca tion between leg health and farm. Detection of estrus was affected by farm, parity, cyclicity, and leg health, but not BCS or milk production. Expression of estrus was compromised in anovular and older cows, and by the timing of the estrus event, but not by gait score, BCS, or milk production. Increased duration of estrus, but not intensity of estrus, improved pregnancy per AI. In conclusion, using an automated activity monitor for the detection of estrus within a Presynch-Ovsynch program resulted in similar pregnancy per AI and days open compared with a reproduction program that was strictly based on timed AI for first postpartum AI. In contrast, notable variations in reproductive outcomes were detected between farms, suggesting that the use of automated activity monitors is prone to individual farm management.

Key words: dairy cow, automated activity monitor, timed artificial insemination, health

\section{INTRODUCTION}

The dairy industry significantly relies on timed AI protocols to synchronize ovulation or estrus for postpartum AI. Surveys have indicated that approximately 75 and $21 \%$ of herds implement an estrus or ovulation synchronization program for the first postpartum AI in the United States and Canada, respectively (Caraviello et al., 2006; Denis-Robichaud et al., 2016). Because of increasing evidence of poor detection of estrus resulting from poor or unidentified expression of estrus (Stevenson, 2001), use of synchronization programs has significantly improved AI submission rates (Chebel et al., 2010) and reduced the duration and variability of the interval from calving to first service (Stevenson, 2001). Although evidence that breeding cows at the time of estrus may result in greater (Tenhagen et al., 2004a; Stevenson and Phatak, 2005; DeJarnette et al., 2001) or similar (DeJarnette et al., 2001) conception rates compared with Ovsynch-like timed AI protocols, overall pregnancy rates are often greater (Cartmill et al., 2001; Cerri et al., 2004) for timed AI protocols be- 
cause all cows are submitted to AI. Synchronization of ovulation allows for management practices to reduce time needed for visual observation of estrus and creates a fixed schedule of AI allowing better planning and use of labor resources. Compliance to injection schedules has been identified as a problem in carrying out protocols successfully (Stevenson and Phatak, 2005).

In spite of the success observed in timed AI programs, concern has increased about the extensive use of hormone therapies in animal production. The dairy industry is not an exception to this trend (Pieper et al., 2016), and more interest from commercial farms and research institutions have aimed to better rationalize the use of pharmacological interventions in reproductive programs (Saint-Dizier and Chastant-Maillard, 2012). The challenge, nonetheless, is to achieve overall herd fertility similar to currently adopted reproductive programs.

In recent years, automated estrus-detection systems, such as pedometers and accelerometers, have become more reliable, with evidence that they are able to correctly identify cattle in estrus (Roelofs et al., 2005; Hockey et al., 2010; Løvendahl and Chagunda, 2010) and properly indicate insemination times by predicting the timing of ovulation (Roelofs et al., 2005; Stevenson et al., 2014). Previous studies have indicated that if detection of estrus can be performed more frequently and during night hours, it reduces the proportion of cattle with unobserved estrus episodes (Hall et al., 1959; Van Vliet and Van Eerdenburg, 1996; Roelofs et al., 2005). Furthermore, Chebel and Santos (2010) demonstrated that visual detection of estrus assisted by tail chalk removal in addition to a timed AI protocol did not result in significantly different pregnancies per AI compared with cows that were subjected to timed AI protocols alone. In fact, a recent survey across Canada demonstrated that dairy producers that adopted automated activity monitors (AAM) found an increase in pregnancy risk from 14.9 to 17.0 between the year before and year after adoption of the AAM (Neves and LeBlanc, 2015). In summary, the incorporation of detection for estrus ("cherry-picking") in timed AI-based reproductive programs has been common practice for many years, but the introduction of AAM has the potential to further minimize pharmacological interventions for efficient breeding programs.

Although strong evidence exists that AAM are capable of detecting cows in estrus, factors that may affect their efficiency are still unclear. Lameness has been shown to decrease walking activity during estrus (Walker et al., 2008) and decrease the number of standing mounts in a given estrus episode (Diskin and Sreenan, 2000). In addition, BCS has also been reported to decrease the expression of estrus (Roelofs et al., 2010; Madureira et al., 2015). Although effects of physical health have been reported using visual observation of estrus behaviors, it is still unclear if factors of physical health also affect the expression of estrus as measured by AAM.

The objective of our study was to investigate the effect of integrating the use of AAM in conjunction with a timed AI protocol on submission rates and pregnancy per AI compared with solely using a timed AI protocol for first AI. Furthermore, we investigated the effects of parity, BCS, milk production, and gait and hock lesion scores on the expression of estrus, as measured by AAM, and the previously mentioned reproductive program treatments.

\section{MATERIALS AND METHODS}

This experiment was conducted between September 2012 and July 2014 at the University of British Columbia's Dairy Education and Research Centre (farm A; Agassiz, BC, Canada) as well as a local commercial dairy farm (farm B) in Dewdney (BC, Canada). All procedures were approved by the Animal Care Committee of the University of British Columbia. The cattle used in this experiment were cared for as outlined by the guidelines provided by the Canadian Council of Animal Care (2009).

\section{Animals and Housing}

A total of 918 high-producing Holstein dairy cows were enrolled in this study from 2 different herds (farm A: $n=466$; farm B: $n=452$ ). The rolling herd average size of each farm was 260 and 350 cows for farms A and $\mathrm{B}$, respectively. Cows produced 12,195 $\pm 2,145$ (farm A) and $12,965 \pm 2,215$ (farm B) $\mathrm{kg}$ of milk (mean \pm SD 305-d mature-equivalent yield) and had a range of BCS from 2 to 4 on both farms at $40 \pm 7$ DIM. Cows from farm A were housed in a naturally ventilated wooden-framed barn with a freestall design, equipped with deep sand-bedded stalls. Cows were milked twice daily at 0500 and $1500 \mathrm{~h}$ with automatic milking machines. Cows from farm B were housed in a naturally ventilated wooden-framed barn equipped with fans and a freestall design; stalls were equipped with mattresses and bedded with sawdust. Farm B milked 3 times daily at 0400,1200 , and $1600 \mathrm{~h}$ with automatic milking machines. Fresh TMR was delivered twice daily on both farms at approximately 0700 and $1600 \mathrm{~h}$. The TMR was formulated following the NRC (2001) guidelines to meet or exceed the requirements of a $620-\mathrm{kg}$ Holstein cow producing $40 \mathrm{~kg} / \mathrm{d}$ of $3.5 \%$ FCM. All cows had ad libitum access to both TMR and water. 


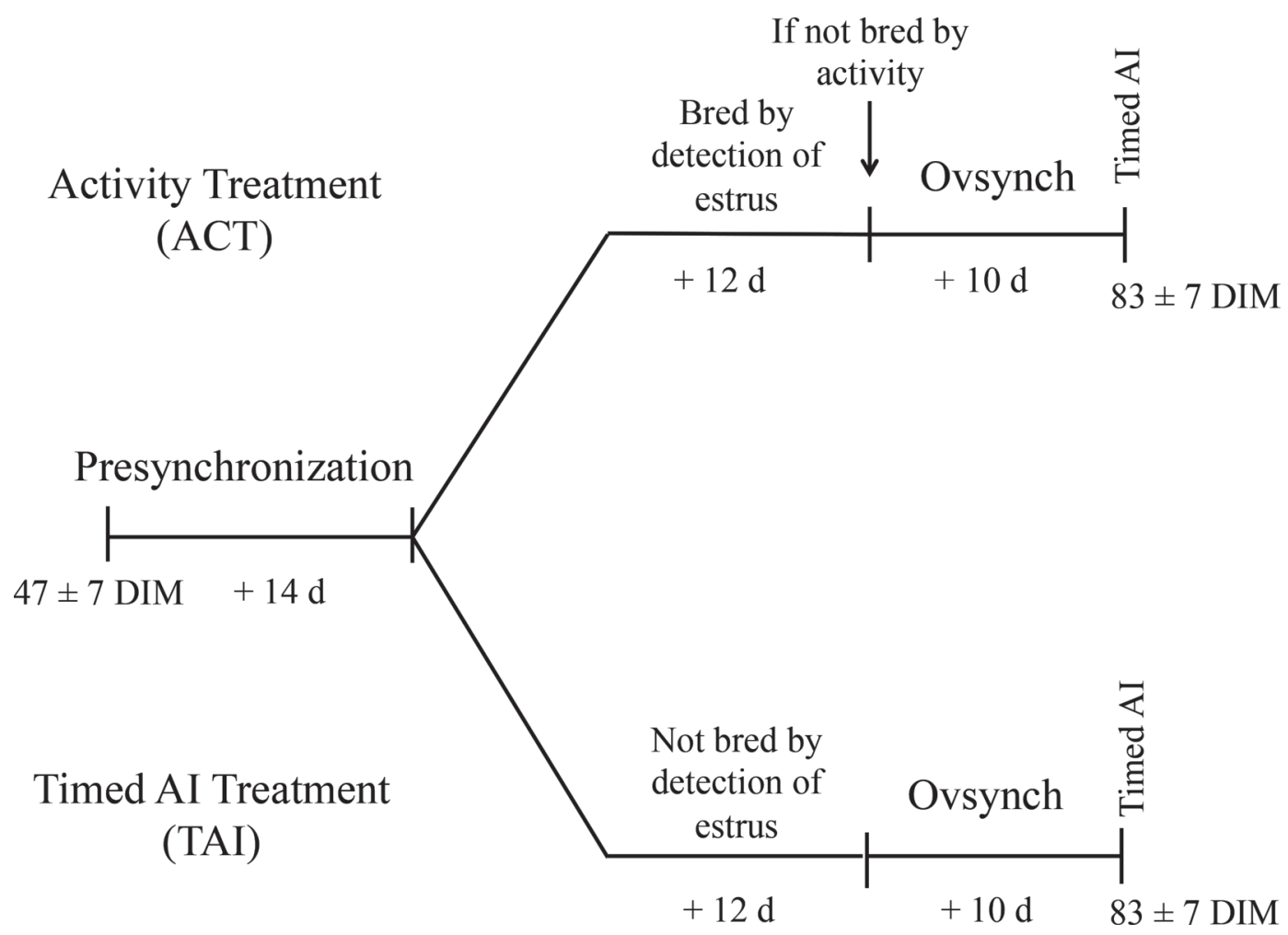

Figure 1. Schematic figure of the reproductive treatments used. Cows were assigned randomly to 2 treatments after a presynchronization protocol. Cows on the ACT treatment (first AI based upon the detection of estrus by automated activity monitors after presynchronization) were bred by detection of estrus, and the remaining unbred cows were enrolled in an Ovsynch 56 protocol and bred by timed AI (TAI). Cows on the TAI treatment were all enrolled in an Ovsynch 56 protocol and bred by timed AI.

\section{Experimental Design}

Cows were assigned randomly to either of 2 treatments based on their ear tag number: (1) all first AI performed by timed AI (TAI), and (2) first AI based upon the detection of estrus by AAM after presynchronization, whereas all remaining non-inseminated cows were enrolled in a timed AI protocol (ACT). All cows were enrolled in a presynchronization protocol at $43 \pm 7$ (farm A) and $40 \pm 7$ DIM (farm B). The presynchronization protocol consisted of 2 injections of $\mathrm{PGF}_{2 \alpha}$ (dinoprost tromethamine, Lutalyse, Zoetis, Florham Park, NJ; 25 mg i.m.) 2 wk apart. Cows from the TAI treatment were automatically enrolled into the Ovsynch-56 protocol $12 \mathrm{~d}$ later. The Ovsynch-56 protocol consisted of 1 injection of $\mathrm{GnRH}$ (gonadorelin hydrochloride, Factrel, Zoetis; $100 \mu \mathrm{g}$ i.m.), followed 1 wk later by an injection of $\mathrm{PGF}_{2 \alpha}$, then $56 \mathrm{~h}$ later by a GnRH injection; finally, AI was performed $16 \mathrm{~h}$ after the final GnRH injection. For the ACT treatment, once the presynchronization protocol was complete, cows were bred upon detection of estrus by the AAM; if cows were not detected in estrus within $12 \mathrm{~d}$ after the second $\mathrm{PGF}_{2 \alpha}$ of the presynchronization they were also enrolled into the Ovsynch-56 protocol. A diagram of each reproductive program is included in Figure 1. The AAM of both farms were checked twice daily for cows in estrus, and breeding was carried out using the a.m./p.m. rule. To understand the practicality of the reproductive programs, treatments included all cows that were enrolled into the entire study, regardless of when they were inseminated. In addition, cows that complied with their specific reproductive program (i.e., were inseminated appropriately according to their treatment) were tested separately.

Cows on both farms were equipped with AAM within 2 wk of parturition. Physical activity was continuously monitored on farm A using SCR Heatime tags (Heatime, SCR Engineering, Netanya, Israel) and on farm B using Afimilk pedometers (AfiAct Pedometer Plus, Afimilk, Kibbutz Afikim, Israel). The threshold activity to be considered an estrus event was set at an activity index of 35 and at a relative increase in activity of $180 \%$ for farm A and B, respectively; an index of 35 approximately equates to a 6 -standard deviation increase in activity compared with baseline for the SCR system. Activity data from farm A were collected and used to determine the effects of BCS, gait, and hock 
scores on the expression of estrus. All estrus episodes ( $\mathrm{n}=666$ from 340 cows) between calving until first AI were used in the analysis. Independent of treatment, the timing of insemination was classified into categories as either occurring at estrus or at the end of a timed AI protocol.

\section{Cow-Level Scoring}

All cows had their body condition, lameness, and hocks scored twice, 2 wk apart, at the time of the presynchronization injections. Body condition was scored on a 5 -point scale from thin (1) to obese (5) as outlined by Edmonson et al. (1989). Cows were later categorized as thin $(\leq 2.75)$ or moderate $(>2.75)$. Lameness was scored on a 5-point scale from normal (1) to severely lame (5) as outlined by Flower and Weary (2006). Cows were later categorized as sound $(\leq 2)$ and lame $(>2)$. Hock lesions were scored on a 4-point scale modified from the Hock Assessment Chart for Cattle developed by Cornell Cooperative Extension (http://hdl.handle. net/1813/36913) as follows: (1) no swelling and without hair missing, (2) minor swelling without hair missing, (3) minor to moderate swelling with bald area, and (4) severe swelling with loss of hair, with or without broken or scabbed skin. Hock lesions were later categorized as normal $(\leq 2)$ and swollen $(>2)$. As hock lesions and lameness were found to be correlated within this study, hock lesion and lameness scores were combined into one score (leg health). Two categories of leg health were created: (1) adequate, cows with both normal hocks and that were sound; and (2) poor, cows with either swollen hocks or that were lame or both. All remaining transition health and production information was collected by the dairy herd personnel with the assistance of the herd veterinarian, and confirmed and recorded by the project leader using the on-farm Dairy Comp 305 software (Valley Agricultural Software, Tulare, CA).

\section{Ultrasonography, Cyclicity, and Pregnancy Diagnosis}

Ovaries were examined by a portable ultrasound (Ibex Pro; E.I. Medical Imaging, Loveland, CO) using a $7.5-\mathrm{MHz}$ linear-array rectal transducer, twice, 2 wk apart, at the time of the presynchronization injections, starting at $43 \pm 7$ (farm A) and $40 \pm 7$ DIM (farm $\mathrm{B})$. Presence and diameter of the largest follicles and corpora lutea were measured and recorded. Cows were classified as cyclic if there was at least 1 corpus luteum present at 1 of the exams and anovular if there was no corpus luteum present at either exam. Pregnancy diagnosis was carried out by ultrasonography by the herd veterinarians at $36 \pm 7 \mathrm{~d}$ post-AI for the detection of an embryonic vesicle with a viable embryo (presence of heartbeat).

\section{Expression of Estrus}

Data from the collar-mounted AAM (Heatime, SCR Engineers) were collected from cows on farm A to determine the effects of treatment, parity, BCS, lameness, and milk production on the expression of estrus; data representing 666 estrus episodes were collected from 340 cows. The effect of hock lesions was excluded, as there was not enough variation in hock lesions on farm A. Expression of estrus was quantified using 2 criteria, (1) peak activity and (2) duration, as previously performed in Madureira et al. (2015). Peak activity was defined as the maximum activity index during an estrus episode. Duration of an estrus episode was defined as the amount of time the cow spent with an index greater than the threshold. The threshold activity to be considered an estrus event was set at an index level of 35 (roughly $6 \mathrm{SD}$ in relation to baseline activity). The timing at which each estrus episode occurred was classified as follows: (1) estrus episodes occurring before the first $\mathrm{PGF}_{2 \alpha}$ of the presynchronization protocol; (2) after the first $\mathrm{PGF}_{2 \alpha}$ and before the second $\mathrm{PGF}_{2 \alpha}$ of the presynchronization protocol; (3) after the second $\mathrm{PGF}_{2 \alpha}$ of the presynchronization protocol but before the start of the Ovsynch protocol; and (4) between the first injection of GnRH until the timed AI of the Ovsynch protocol. Specific estrus-expression traits could not be collected on farm B.

\section{Statistical Analyses}

All analyses for this experiment were performed using SAS (version 9.4; SAS Inst. Inc., Cary, NC) with cow as the experimental unit. Before all analyses, data were tested for normality using the UNIVARIATE procedure and probability distribution plots; any variables deemed not normal were transformed to fit normality and subsequently back-transformed for geometric means. Treatment, compliance to treatment, and AI category as well as peak activity and duration were always tested in separate models throughout the entire statistical analysis because of collinearity.

The effects of treatment, AI category, farm, parity, cyclicity, BCS, leg health, and milk production on the dichotomous variables pregnancy outcome and detection of estrus were tested with logistic regression using the LOGISTIC procedure with backward elimination using Wald's statistic criterion when $P<0.15$. For the analysis of the expression of estrus, the peak activity and duration variables were considered dependent variables and tested for the effects of parity, cyclicity, 
Table 1. Frequency distributions of explanatory variables for the entire study and stratified by farm

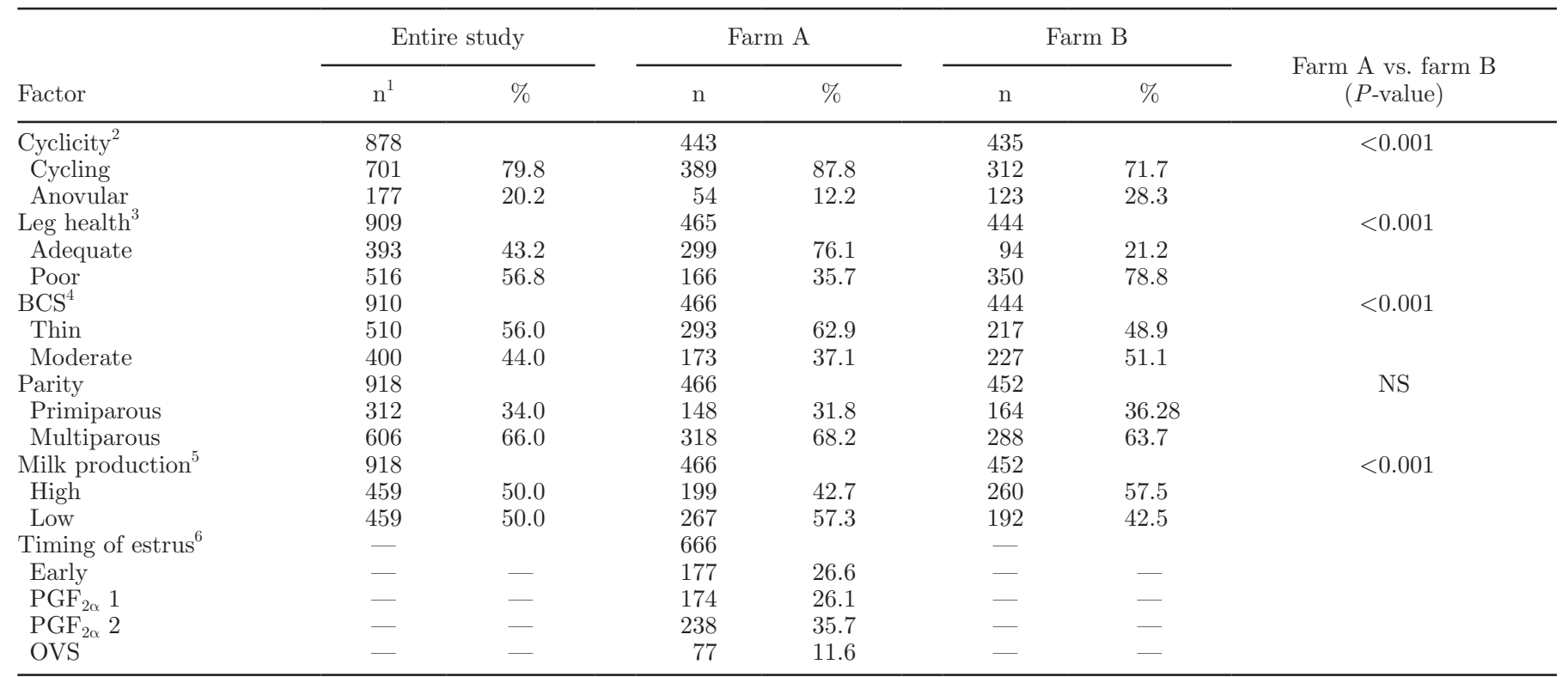

${ }^{1}$ Does not always total to 918 cows per variable due to missing observations.

${ }^{2}$ Cycling was defined as the presence of at least one corpus luteum present at 1 of 2 ultrasound exams performed at the time of the presynchronization.

${ }^{3}$ Leg health was defined as adequate if the cow had a hock and gait score both $\leq 2$; cows with either a hock score, gait score, or both $>2$ were considered as having poor leg health.

${ }^{4} \mathrm{BCS} \leq 2.75$ was defined as thin, whereas $>2.75$ was defined as moderate.

${ }^{5}$ Milk production was measured as the 305-d mature-equivalent yield and divided into 2 groups using the median.

${ }^{6}$ Data only available for Farm A. Timing of estrus was classified as follows: early = estrus episodes occurring before the first PGF ${ }_{2 \alpha}$ of the presynchronization protocol, $\mathrm{PGF}_{2 \alpha} 1=$ after the first $\mathrm{PGF}_{2 \alpha}$ and before the second $\mathrm{PGF}_{2 \alpha}$ of the presynchronization protocol, $\mathrm{PGF} \mathrm{F}_{2 \alpha} 2=$ after the second $\mathrm{PGF}_{2 \alpha}$ of the presynchronization protocol but before the start of the Ovsynch protocol; and OVS = between the first injection of $\mathrm{GnRH}$ and timed AI of the Ovsynch protocol.

BCS, leg health, milk production, and the timing of the estrus using ANOVA for repeated measures with cow as the subject using the MIXED procedure. Frequency distributions of all explanatory variables are summarized for the entire study and by farm in Table 1 .

Effects of treatment, compliance to treatment, and AI category on hazard risk of pregnancy by 300 DIM were analyzed with PHREG procedure of SAS. Cox proportional hazard regression models included days open as the outcome variable and treatment, compliance to treatment, AI category, farm, parity, cyclicity, BCS, leg health, and milk production as explanatory variables. Observations were right-censored at culling or at 300 DIM if pregnancy had not been previously confirmed. Only variables with $P \leq 0.15$ were kept in the final models. Survival curves were drawn from the proportion of nonpregnant cows at each time point given by the LIFETEST procedure.

\section{RESULTS}

Overall pregnancy per AI did not differ between treatments (30.8 vs. $33.5 \%$ for ACT and TAI treatments;
$P=0.39$ ). Compliance within the TAI treatment was $83.2 \%$, where $16.8 \%$ of cows on the TAI treatment were bred by estrus at some point after the second $\mathrm{PGF}_{2 \alpha}$ and before the end of the Ovsynch protocol, instead of at the scheduled timed AI. Compliance on farm A was $87.3 \%$ and on farm B was $77.8 \%$. With inclusion of only cows that were inseminated compliant to their assigned treatment $(\mathrm{n}=779)$, pregnancy per AI was still not different between treatments for the entire study (30.8 vs. $35.9 \%$ for ACT and TAI treatments; $P=0.13$ ). This lack of an effect was consistent for farm B (31.1 vs. $31.3 \%$ for $\mathrm{ACT}$ and TAI treatments; $P=0.97$ ), but not for farm A (30.5 vs. $40.0 \%$ for ACT and TAI treatments; $P=0.04)$.

Estrus was detected for $50.5 \%$ of cows; detection of estrus was determined as the proportion of cows in the ACT treatment bred by estrus between the end of presynchronization and the beginning of the Ovsynch protocol. We found a substantial difference in the detection of estrus between farms, as farm A had $65.1 \%$ of cows detected in estrus, whereas farm B detected $34.4 \%$ of their cows in estrus after the presynchronization $(P<$ $0.01)$. When only cyclic cows were analyzed, detection 
of estrus was $52.2 \%$ for the entire study and 66.0 and $35.3 \%$ for farm A and farm B, respectively. Although cyclicity differed by farm ( 87.8 vs. $71.7 \%$ for farm A and farm $\mathrm{B}$, respectively; $P<0.001$ ), it does not seem to be the sole reason for this difference in detection of estrus. Pregnancy was affected by AI category, where the odds of a cow bred at timed AI to become pregnant were 1.48 times greater than the odds of a cow that was bred at estrus $(P=0.02)$. In contrast, cows bred at timed AI were bred at significantly later DIM than those bred at estrus $(75.7 \pm 0.2$ vs. $63.2 \pm 0.3$ DIM; Table 2). A summary of pregnancy per AI found for treatment and AI category (insemination at estrus or timed AI) is presented in Table 2 for the entire study and by farm.

Pregnancy success at first postpartum AI was affected by parity $(P<0.01)$, cyclicity $(P=0.03)$, BCS $(P<0.01)$, milk production $(P=0.03)$, and a tendency for leg health $(P=0.10)$; these results are summarized in Table 3 for the entire study and for cows that were compliant to the treatment. Additional interactions were found for treatment by parity $(P=0.02)$, treatment by cyclicity $(P=0.07)$, and leg health by parity $(P=0.10)$. Pregnancy outcomes were not affected by farm $(P=0.90)$ or treatment $(P=0.33)$. In contrast, when only including cows that were intended to be treated, we found a tendency for an effect of treatment on pregnancy outcomes $(P=0.09$; Table 3$)$. Within the treatment by parity interaction, primiparous cows on the ACT treatment had 2.36 greater odds of pregnancy than multiparous cows on the ACT treatment; alternatively, we noted no difference in odds of pregnancy between primiparous and multiparous cows enrolled in the TAI treatment $(P=0.02$; Table 4$)$. We observed a tendency for primiparous cows with adequate leg health to have 1.83 greater odds of pregnancy than primiparous; however, no effect of leg health was noted on the odds of pregnancy in multiparous cows $(P=0.10$; Table 4). We found also a tendency for a treatment by cyclicity interaction, as cyclicity status did not affect the odds of pregnancy on the TAI treatment, but cyclic cows enrolled in the ACT treatment had 2.46 greater odds of pregnancy than anovulatory cows enrolled in the TAI treatment $(P=0.07$; Table 4$)$. Pregnancy outcome interactions for the entire study in addition to those that were compliant to the treatment are summarized in Table 4.

Analyzing pregnancy outcomes stratified by farm enabled us to see distinct differences in factors that affected pregnancy success. On farm A, parity $(P=$ $0.02)$, cyclicity $(P=0.05)$, and BCS $(P<0.01)$ affected successful pregnancy outcomes, whereas on farm

Table 2. Pregnancy per AI (P/AI) and DIM (mean $\pm \mathrm{SE})$ for treatments $\left(\mathrm{ACT}\right.$ vs. TAI) ${ }^{1}$ cows compliant with the treatment ${ }^{1}(\mathrm{ACT}$ vs. TAI), and AI categories (estrus vs. timed AI) for the entire study and stratified by farm

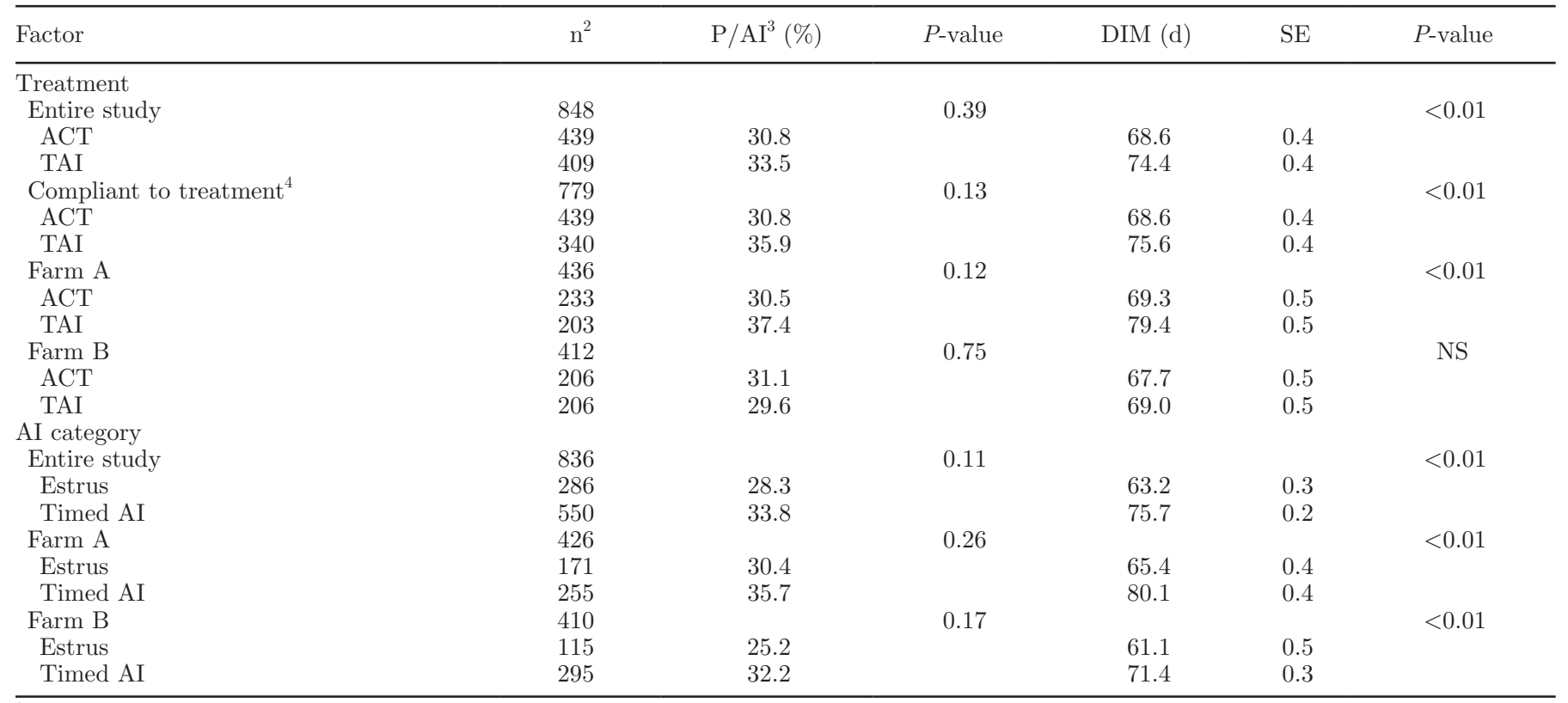

${ }^{1}$ Treatments were (1) first insemination performed by timed AI (TAI) and (2) first insemination based on the detection of estrus by activity monitors after the presynchronization, whereas all remaining noninseminated cows were enrolled in a timed AI protocol (ACT).

${ }^{2}$ Does not total 918 due to missing pregnancy diagnoses.

${ }^{3}$ Calculated using frequency tables by proc FREQ of SAS (SAS Institute Inc., Cary, NC).

${ }^{4}$ Cows compliant to treatment excludes any cows that were inseminated outside of the proposed treatment. 
Table 3. Pregnancy per AI (P/AI) and odds ratios (OR) with $95 \%$ CI for pregnancy outcomes for the entire study and for cows that were inseminated correctly according to their assigned treatment (compliant to treatment)

\begin{tabular}{|c|c|c|c|c|c|c|c|c|}
\hline Factor & $\begin{array}{c}\mathrm{P} / \mathrm{AI} \\
\left(\% ; \text { no. } / \text { no. }^{1}\right)\end{array}$ & \multicolumn{3}{|c|}{ Entire study } & $\begin{array}{c}\mathrm{P} / \mathrm{AI} \\
(\% ; \text { no. } / \text { no. })\end{array}$ & \multicolumn{3}{|c|}{ Compliant to treatment } \\
\hline Treatment $^{2}$ & 848 & & & NS & 779 & & & 0.09 \\
\hline TAI & $33.5(137 / 409)$ & & & & $35.9(122 / 340)$ & 1.13 & $0.96-1.80$ & \\
\hline Parity & 848 & & & $<0.01$ & 779 & & & $<0.01$ \\
\hline Primiparous & $41.4(123 / 297)$ & 1.60 & $1.15-2.23$ & & $43.5(117 / 269)$ & 1.75 & $1.24-2.46$ & \\
\hline Cycling & $34.1(223 / 655)$ & 1.56 & $1.04-2.34$ & & $35.4(214 / 605)$ & 1.77 & $1.14-2.74$ & \\
\hline Anovular & $23.8(39 / 164)$ & Referent & & & $22.8(33 / 145)$ & Referent & & \\
\hline $\mathrm{BCS}^{4}$ & 843 & & & $<0.01$ & 774 & & & $<0.01$ \\
\hline Low & $25.9(118 / 456)$ & Referent & & & $26.8(113 / 422)$ & Referent & & \\
\hline Moderate & $39.5(153 / 387)$ & 1.63 & $1.20-2.23$ & & $40.6(143 / 352)$ & 1.58 & $1.15-2.19$ & \\
\hline Milk production $^{5}$ & 848 & & & 0.03 & 779 & & & 0.04 \\
\hline Low & $35.7(142 / 398)$ & 1.41 & $1.04-1.90$ & & $36.7(135 / 368)$ & 1.40 & $1.02-1.92$ & \\
\hline
\end{tabular}

${ }^{1}$ Does not total 918 due to missing pregnancy diagnoses.

${ }^{2}$ Treatments were (1) first insemination performed by timed AI (TAI) and (2) first insemination based on the detection of estrus by activity monitors after the presynchronization, whereas all remaining noninseminated cows were enrolled in a timed AI protocol (ACT).

${ }^{3}$ Cycling was defined as the presence of at least one corpus luteum present at 1 of 2 ultrasound exams performed at the time of the presynchronization.

${ }^{4} \mathrm{BCS} \leq 2.75$ was defined as thin, whereas $>2.75$ was defined as moderate.

${ }^{5}$ Milk production was measured as the 305-d mature-equivalent yield and divided into 2 groups using the median.

${ }^{6}$ Leg health was defined as adequate if the cow had a hock and gait score both $\leq 2$; cows with a hock score, gait score, or both $>2$ were considered as having poor leg health.

B, BCS $(P=0.02)$, milk production $(P=0.02)$, and leg health $(P=0.06)$ affected successful pregnancy outcomes (Table 5).

Factors that affected the odds of cows being detected in estrus after the presynchronization protocol (Table 6) were farm $(P<0.001)$, parity $(P<0.01)$, and cyclicity $(P=0.08)$. The proportion of cows detected in estrus was different for cows that had poor and adequate leg health, where fewer cows with poor leg health were detected in estrus ( 40.8 vs. $62.0 \% ; P<0.001$ ). Frequency distributions and odds ratios for the detection of estrus are summarized in Table 6 .

Factors affecting the hazard of pregnancy by 300 DIM were farm, parity, BCS, as well as a treatment by cyclicity interaction and a leg health by farm interaction. Farm B had an increased hazard of pregnancy [hazard ratio $(\mathbf{H R})=1.21 ; P=0.01]$, whereas the hazard of pregnancy was decreased in multiparous cows $(\mathrm{HR}=0.66 ; P<0.001)$ as well as in thin cows $(\mathrm{HR}=$ $0.78 ; P<0.01)$. An interaction between cyclicity and treatment was found, where cows on the TAI treatment were unaffected by cyclicity $(\mathrm{HR}=1.00 ; P=0.04)$, but cows that were not cycling by 50 DIM within the ACT treatment had a reduced hazard of pregnancy in comparison with those that were cycling $(\mathrm{HR}=0.74 ; P=$ 0.04). Inclusion of only cows that were compliant with the treatment did not change the effect of treatment on hazard of pregnancy $(P>0.10)$, but a tendency for a farm by leg health interaction was found $(P=0.08)$. On farm A, leg health had no effect on hazard of pregnancy $(\mathrm{HR}=1.00 ; P=0.08)$; however, on farm B cows with poor leg health had a decreased hazard of pregnancy $(\mathrm{HR}=0.77 ; P=0.08)$. The AI category was found to have an effect on hazard of pregnancy, where cows bred at the time of estrus for their first postpartum insemination had a greater hazard of pregnancy than those bred at the end of the timed AI protocol ( HR = $1.19 ; P=0.03)$. Survival curves of hazard of pregnancy by $300 \mathrm{DIM}$ for treatment, compliance to treatment, AI category, and cyclicity by treatment and leg health by farm interactions are presented in Figure 2.

The mean and range duration and intensity of estrus were found to be $11.1 \mathrm{~h} \pm 5.0$ ( 2 to $24 \mathrm{~h}$ ) and $73.6 \pm$ 20.1 (35 to 100), respectively. Estrous expression was not affected by BCS, gait score, or milk production; we did not find enough variation in hock score within the subset of data to be included within the analysis. Cyclicity affected estrous expression, where cows that were cycling by 50 DIM had estrus episodes with greater peak activity (67.0 vs. 74.1 index; $P=0.02)$ and a longer duration (9.0 vs. $11.2 \mathrm{~h} ; P<0.01)$. Primiparous cows were found to have estrus episodes with 
Table 4. Pregnancy per AI (P/AI) and odds ratios (OR) with $95 \%$ CI for pregnancy outcome interactions for the entire study and for cows that were inseminated correctly according to their assigned treatment (compliant to treatment) using a multivariable logistic regression

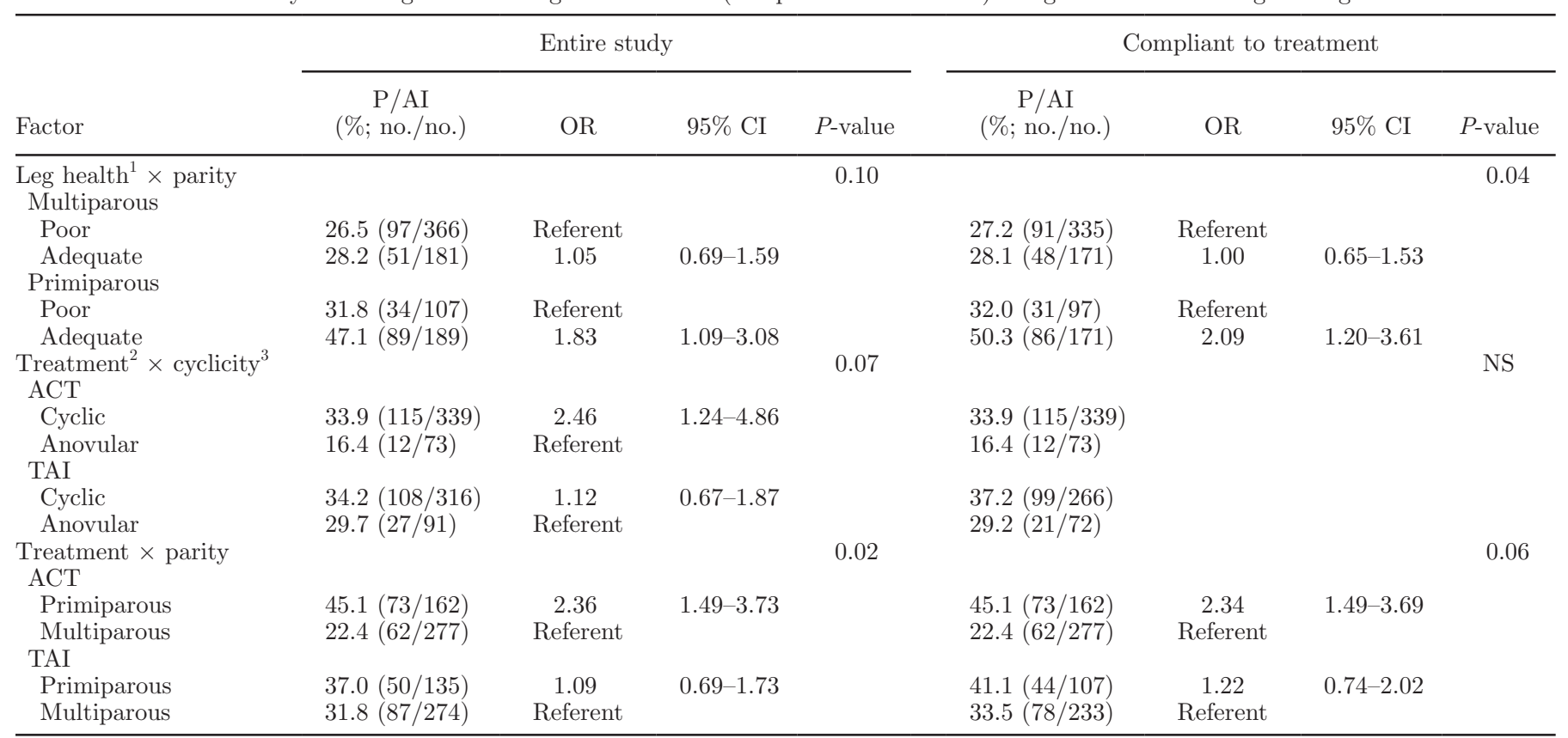

${ }^{1}$ Leg health was defined as adequate if the cow had a hock and gait score both $\leq 2$, cows with a hock score, gait score, or both $>2$ were considered as having poor leg health.

${ }^{2}$ Treatments were (1) first insemination performed by timed AI (TAI) and (2) first insemination based on the detection of estrus by activity monitors after the presynchronization, whereas all remaining noninseminated cows were enrolled in a timed AI protocol (ACT).

${ }^{3}$ Cycling was defined as the presence of at least one corpus luteum present at 1 of 2 ultrasound exams performed at the time of the presynchronization.

greater peak activity $(P<0.01)$ and longer duration $(P$ $<0.01$ ) than multiparous cows (Table 7 ). We noted an effect of the timing of the estrus episode on the expression of estrus $(P<0.001$; Table 7$)$. Estrus episodes that occurred before enrollment in the experiment had lower peak activity and a shorter duration than episodes occurring at any other time. Expression of estrus occurring during the Ovsynch protocol tended to be lower than those after the second prostaglandin, but the same as estrus occurring after the first prostaglandin; estrus occurring after the first and second prostaglandins did not differ (Table 7). Finally, when only including estrus events that were measured by the AAM and AI was performed (farm $A ; n=199$ ), estrus events with longer duration were more likely to result in pregnancy, where the odds of pregnancy for a long estrus event was 2.2 times greater than the odds of short estrus events $(P=$ $0.02)$; we found no effect of peak activity on pregnancy outcomes in this study.

\section{DISCUSSION}

Incorporation of the detection of estrus during a Presynch-Ovsynch program for first AI in lactating dairy cows is a practice commonly used on North American dairy farms. In general, the challenge is to measure and compare success rates (detection of estrus and pregnancy per AI) of farm reproductive-management programs that use different protocols, voluntary waiting periods, and have farm differences in milk production, thermal stress, and general housing and management conditions. Previous studies have shown that cherry-picking after the end of a $\mathrm{PGF}_{2 \alpha}$-based presynchronization protocol can be efficient and comparable (hazard ratios for days to conception) with timed AI only programs (Neves et al., 2012; Neves and LeBlanc, 2015; Dolecheck et al., 2016); however, this is not always the case when comparing only pregnancy success at first AI. The increase in AAM available on the market has created more options for producers to potentially increase estrus detection rates and modify current reproduction programs. Incorporation of these new technologies lead to questions about factors that may alter their effectiveness. This study showed that using AAM for the detection of estrus within a Presynch-Ovsynch program resulted in similar pregnancy per AI compared with a reproduction program that was strictly based on timed AI. This and other studies (Neves et al., 2012; Valenza et al., 2012; Fricke et al. 2014b; Dolecheck et al., 2016) also found a strong effect of farm, suggesting that the use 
Table 5. Pregnancy per AI (P/AI) and odds ratios (OR) with $95 \%$ CI for pregnancy outcomes stratified by farm

\begin{tabular}{|c|c|c|c|c|c|c|c|c|}
\hline \multirow[b]{2}{*}{ Factor } & \multicolumn{4}{|c|}{ Farm A } & \multicolumn{4}{|c|}{ Farm B } \\
\hline & $\begin{array}{c}\mathrm{P} / \mathrm{AI} \\
(\% ; \text { no. } / \text { no. })\end{array}$ & OR & $95 \% \mathrm{CI}$ & $P$-value & $\begin{array}{c}\mathrm{P} / \mathrm{AI} \\
(\% ; \text { no. } / \text { no. })\end{array}$ & OR & $95 \%$ CI & $P$-value \\
\hline $\mathrm{ACT}$ & $30.4(71 / 233)$ & & & & $31.1(64 / 206)$ & & & \\
\hline TAI & $37.4(76 / 203)$ & & & & $29.6(61 / 206)$ & & & \\
\hline Parity & & & & $<0.01$ & & & & NS \\
\hline Cyclicity $^{2}$ & & & & 0.02 & & & & NS \\
\hline Cycling & $35.9(131 / 365)$ & 2.64 & $1.19-5.86$ & & $31.7(92 / 290)$ & & & \\
\hline Anovular & $16.3(8 / 49)$ & & & & $27.0(31 / 115)$ & & & \\
\hline $\mathrm{BCS}^{3}$ & & & & 0.03 & & & & $<0.01$ \\
\hline Low & $28.6(76 / 266)$ & Referent & & & $22.1(42 / 190)$ & Referent & & \\
\hline Moderate & $41.8(71 / 170)$ & 1.59 & $1.03-2.43$ & & $37.8(82 / 217)$ & 1.91 & $1.21-3.01$ & \\
\hline Milk production ${ }^{4}$ & & & & NS & & & & 0.03 \\
\hline
\end{tabular}

${ }^{1}$ Treatments were (1) first insemination performed by timed AI (TAI) and (2) first insemination based on the detection of estrus by activity monitors after the presynchronization, whereas all remaining noninseminated cows were enrolled in a timed AI protocol (ACT).

${ }^{2}$ Cycling was defined as the presence of at least one corpus luteum present at 1 of 2 ultrasound exams performed at the time of the presynchronization.

${ }^{3} \mathrm{BCS} \leq 2.75$ was defined as thin, whereas $>2.75$ was defined as moderate.

${ }^{4}$ Milk production was measured as the 305-d mature-equivalent yield and divided into 2 groups using the median.

${ }^{5}$ Leg health was defined as adequate if the cow had a hock and gait score both $\leq 2$; cows with either a hock score, gait score, or both $>2$ were considered as having poor leg health.

of AAM are likely more prone to individual variations, particularly when compared with more established timed AI protocols. In addition, our study showed that lameness had a negative effect on pregnancy success on the farm with a greater prevalence of leg health injuries and the repercussions of this are seen in increased days

Table 6. Factors affecting the proportion and odds ratio (OR) with $95 \%$ CI of cows detected in estrus after a presynchronization protocol using an automated activity monitor

\begin{tabular}{|c|c|c|c|c|c|}
\hline Factor & $\begin{array}{l}\text { Estrous detection } \\
(\% ; \text { no. } / \text { no. })\end{array}$ & $P$-value & OR & $95 \% \mathrm{CI}$ & $P$-value \\
\hline Farm & 444 & $<0.001$ & & & $<0.001$ \\
\hline Farm A & $65.1(151 / 232)$ & & 3.47 & $2.29-5.27$ & \\
\hline Farm B & $34.4(73 / 212)$ & & Referent & & \\
\hline Cyclcity $^{1}$ & 420 & $<0.01$ & & & 0.08 \\
\hline Cycling & $52.2(181 / 347)$ & & 1.64 & $0.94-2.87$ & \\
\hline Anovular & $34.3(25 / 73)$ & & Referent & & \\
\hline Parity & 444 & 0.01 & & & $<0.01$ \\
\hline Primiparous & $58.2(92 / 158)$ & & 1.82 & $1.18-2.81$ & \\
\hline Multiparous & $46.2(132 / 286)$ & & Referent & & \\
\hline $\mathrm{BCS}^{2}$ & 440 & NS & & & NS \\
\hline Low & $49.6(122 / 246)$ & & & & \\
\hline Moderate & $51.6(100 / 194)$ & & & & \\
\hline Leg health ${ }^{3}$ & 440 & $<0.001$ & & & NS \\
\hline Poor & $40.8(98 / 240)$ & & & & \\
\hline Adequate & $62.0(124 / 200)$ & & & & \\
\hline
\end{tabular}

${ }^{1}$ Cycling was defined as the presence of at least one corpus luteum present at 1 of 2 ultrasound exams performed at the time of the presynchronization.

${ }^{2} \mathrm{BCS} \leq 2.75$ was defined as thin, whereas $>2.75$ was defined as moderate.

${ }^{3} \mathrm{Leg}$ health was defined as adequate if the cow had a hock and gait score both $\leq 2$; cows with a hock score, gait score, or both $>2$ were considered as having poor leg health. 
until conception. Leg health and poor BCS had no effect on peak intensity or duration of estrus as measured by AAM.

Within our study, cows bred at timed AI were more likely to become pregnant than those bred at the time of estrus; however, cows bred at estrus for their first

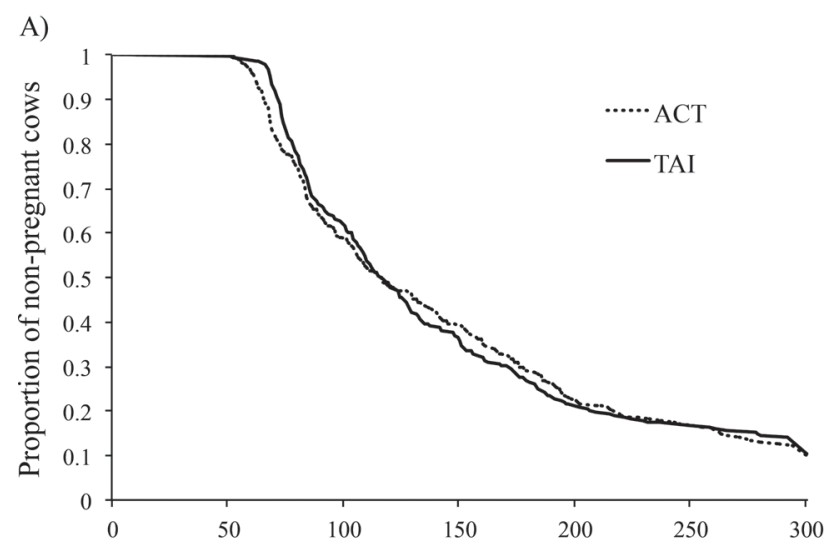

B)

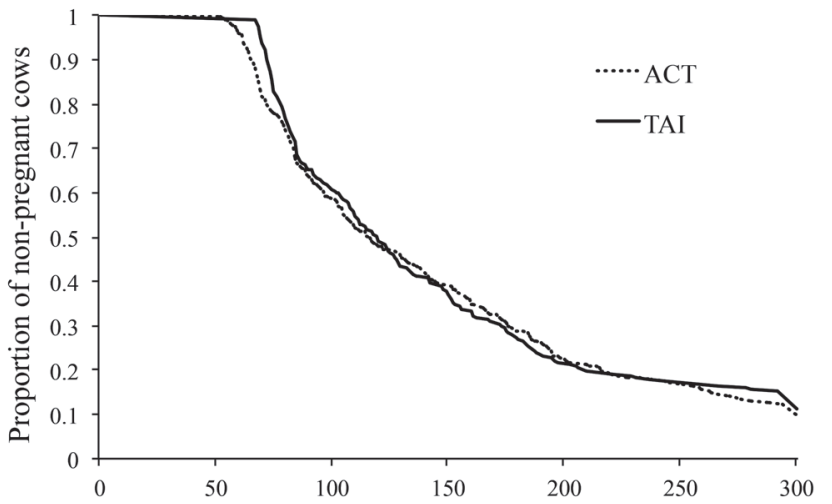

E)

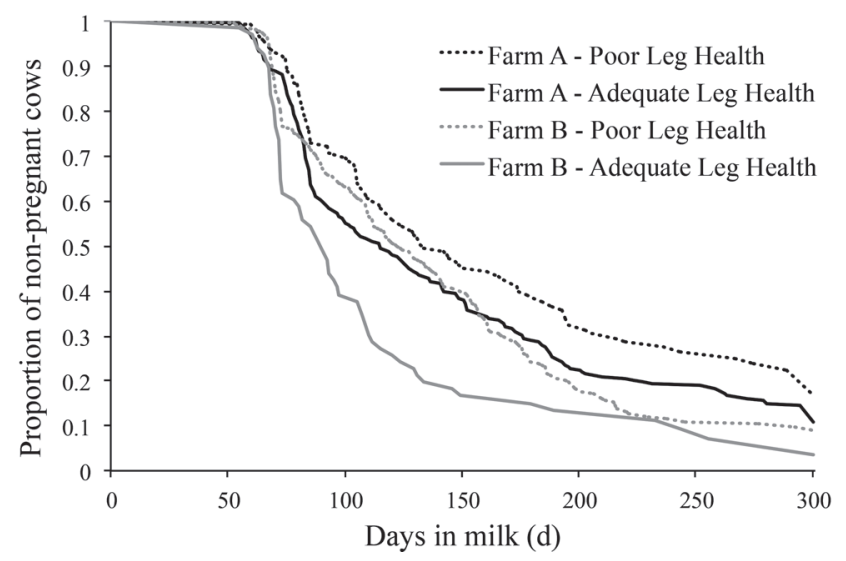

postpartum AI were found to have shorter days to conception than those bred at timed AI. These results agree with previous reports of an increase in pregnancy per AI when insemination were carried out at timed AI when in comparison with those at estrus (Cerri et al., 2004; Gumen et al., 2012; Fricke et al., 2014b, Ste-

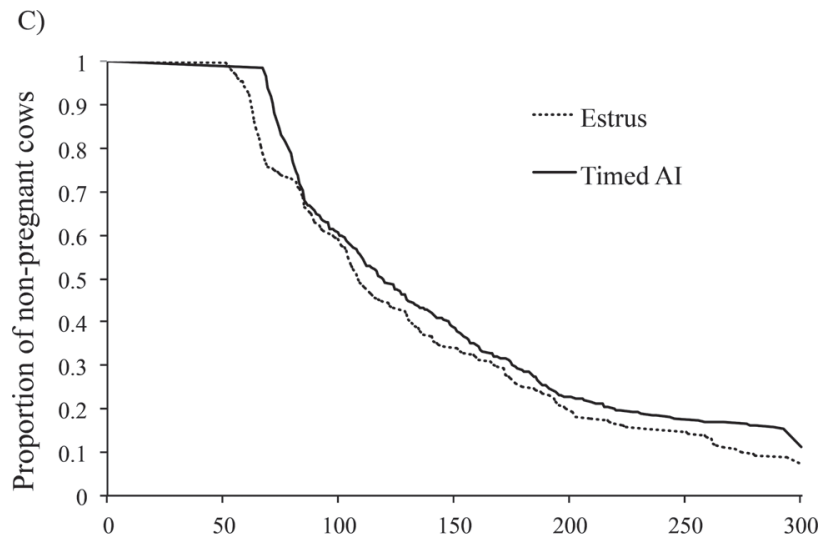

D)

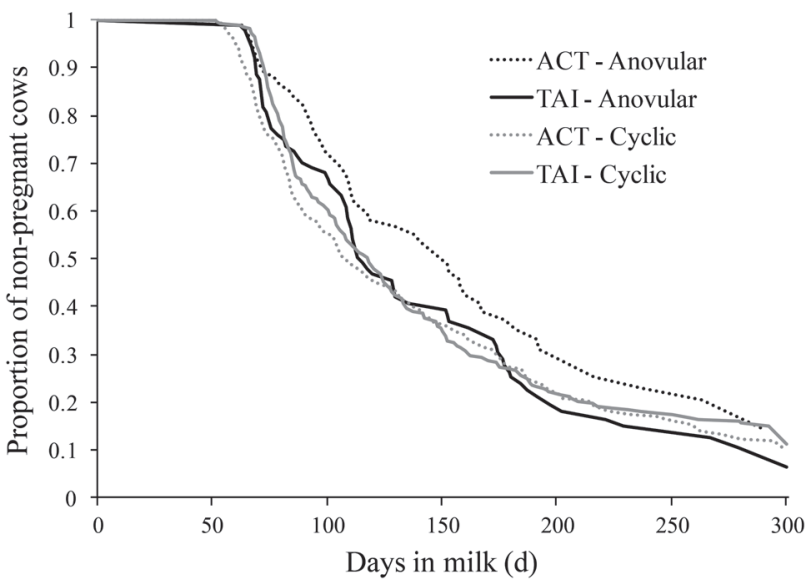

Figure 2. Survival curves of DIM to conception until 300 DIM for $(A)$ treatment $(P>0.05)$, (B) cows compliant to both treatments, $(C)$ AI category (insemination at estrus or timed AI; $P=0.03)$, (D) treatment by cyclicity interaction $(P=0.04)$, and $(\mathrm{E})$ farm by leg health interaction $(P=0.08)$. TAI $=$ all first AI performed by timed AI; ACT $=$ first AI based upon the detection of estrus by automated activity monitors after presynchronization. 
Table 7. Factors affecting estrous expression parameters, peak activity ${ }^{1}$ and duration ${ }^{2}$ (LSM \pm SE), as measured by an automated activity monitor

\begin{tabular}{|c|c|c|c|c|c|c|}
\hline Factor & $\begin{array}{l}\text { Peak activity } \\
\quad \text { (index) }\end{array}$ & $\mathrm{SE}$ & $P$-value & $\begin{array}{l}\text { Duration } \\
\text { (h) }\end{array}$ & $\mathrm{SE}$ & $P$-value \\
\hline Cyclicity $^{3}$ & & & 0.07 & & & 0.02 \\
\hline Cycling & 74.2 & 0.99 & & 11.3 & 0.25 & \\
\hline Anovular & 68.6 & 2.90 & & 9.6 & 0.72 & \\
\hline Parity & & & $<0.01$ & & & $<0.01$ \\
\hline Primiparous & 74.3 & 1.93 & & 11.1 & 0.48 & \\
\hline Multiparous & 68.5 & 1.63 & & 9.8 & 0.42 & \\
\hline $\mathrm{BCS}^{4}$ & & & NS & & & NS \\
\hline Low & 71.4 & 1.71 & & 10.5 & 0.42 & \\
\hline Moderate & 71.5 & 1.87 & & 10.3 & 0.47 & \\
\hline Timing of estrus ${ }^{5}$ & & & $<0.01$ & & & $<0.01$ \\
\hline Early & $65.4^{\mathrm{b}}$ & 2.00 & & $9.0^{\mathrm{a}}$ & 0.50 & \\
\hline $\mathrm{PGF}_{2 \alpha} 1$ & $73.3^{\mathrm{bc}}$ & 1.97 & & $10.7^{\mathrm{b}}$ & 0.49 & \\
\hline $\mathrm{PGF}_{2 \alpha} 2$ & $75.6^{\mathrm{c}}$ & 1.90 & & $11.6^{\mathrm{c}}$ & 0.47 & \\
\hline OVS & $71.4^{\mathrm{b}}$ & 2.49 & & $10.4^{\mathrm{b}}$ & 0.62 & \\
\hline
\end{tabular}

${ }^{\mathrm{a}-\mathrm{c}}$ Values with different superscripts in the same column are significantly different $(P<0.05)$.

${ }^{1}$ Peak activity was defined as the highest index measured by the automated activity monitor.

${ }^{2}$ Duration was measured as the time (h) the index spent above the activity threshold.

${ }^{3}$ Cycling was defined as the presence of at least one corpus luteum present at 1 of 2 ultrasound exams performed at the time of the presynchronization.

${ }^{4} \mathrm{BCS} \leq 2.75$ was defined as thin, whereas $>2.75$ was defined as moderate.

${ }^{5}$ Timing of estrus was classified as follows: early $=$ estrus episodes occurring before the first $\mathrm{PGF}_{2 \alpha}$ of the presynchronization protocol, $\mathrm{PGF}_{2 \alpha} 1$ = after the first $\mathrm{PGF}_{2 \alpha}$ and before the second $\mathrm{PGF}_{2 \alpha}$ of the presynchronization protocol, $\mathrm{PGF}_{2 \alpha} 2=$ after the second $\mathrm{PGF}_{2 \alpha}$ of the presynchronization protocol but before the start of the Ovsynch protocol; and OVS = between the first injection of GnRH and timed AI of the Ovsynch protocol.

venson et al., 2014). These results are in contrast to others that found no difference at first postpartum AI (Gümen et al., 2003; Dalton et al., 2005; Chebel and Santos, 2010) or subsequent AI (Giordano et al., 2015; Dolecheck et al., 2016). The experimental design of our study and other similarly designed studies make it difficult to conclude the major cause for this difference (or lack thereof) in fertility between the 2 categories of inseminations, considering cows detected in estrus were bred approximately $10 \mathrm{~d}$ earlier than cows bred in the TAI treatment. Previous studies have reported that fewer DIM at first breeding can have negative effects on conception rates (Tenhagen et al., 2003; Stevenson and Phatak, 2005), but no studies have compared the 2 categories at similar DIM. We found no longer-term effects of treatment on average days open for the 2 groups. This is consistent with other studies (Neves et al., 2012; Fricke et al., 2014b; Dolecheck et al., 2016), which reported no difference in days to conception between ACT and TAI reproductive programs. In contrast, Neves et al. (2012) found a reduction in days from calving to pregnancy when they only included cows that were compliant to their respective programs. In addition, some studies have found reproductive programs based on inseminations at estrus to have shorter days open, even if they have reduced pregnancy per AI at first $\mathrm{AI}$ when comparing inseminations occurring at estrus versus timed AI (Stevenson et al., 2014).
Duration of estrus found in the present study was similar to those reported in Madureira et al. (2015), as well as others using AAM (Roelofs et al., 2005; Aungier et al., 2012), but shorter than reported by Valenza et al. (2012). Furthermore, research reporting the duration of estrus using visual observations also found similar values (13.4 h, Roelofs et al., 2004; and $11.8 \mathrm{~h}$, Roelofs et al., 2005). Consistent with the present study, Madureira et al. (2015) reported that pregnancy per AI increases with increased expression of estrus as measured using 2 different AAM (neck and leg mounted). Although we did not detect an effect of estrus intensity on pregnancy per AI, as was found in Madureira et al. (2015), we did observe an effect of estrus duration on fertility. The lack of an effect by intensity may be due in part to the small numbers of cows that had both estrous expression data and were inseminated. Estrous expression was found to be different when DIM of the estrus event was considered. Estrus episodes that occurred before the presynchronization had the lowest estrous expression and events after the second $\mathrm{PGF}_{2 \alpha}$ had the highest, but whether this is an effect of DIM or an effect of hormone intervention cannot be concluded from the current study.

It was hypothesized that cows with poor BCS would have limited expression of estrus due to negative energy balance (Butler, 2003) and delays in cyclicity (Chebel and Santos, 2010). Another study from our group also 
found significant effects of BCS on estrous expression (Madureira et al., 2015). In the present study, we found that BCS did not affect detection or expression of estrus after a synchronization protocol but it did affect the likelihood of successful pregnancy on both farms.

Lameness was not found to have an effect on the expression of estrus as measured by the AAM. Previous research has demonstrated a reduction in daily steps (López-Gatius et al., 2005; O'Callaghan et al., 2003) and steps at the time of estrus (Walker et al., 2008) in lame cows. Alternatively, Chapinal et al. (2010) found no change in daily steps between lame and nonlame cows, but did find that lame cows walked slower and spent more time lying down per day. Other studies using leg-mounted accelerometers and pedometers have found changes in walking activity caused by lameness (Alsaaod et al., 2012; de Mol et al., 2013; Thorup et al., 2015); however, little research has measured activity using a neck-mounted accelerometer at the time of estrus (in contrast to daily activity), as performed in the current study.

Previous research on the detection of estrus after estrus synchronization protocols have found anywhere from 66 to $71 \%$ of the cows in estrus using AAM (Valenza et al., 2012; Fricke et al., 2014b). On the other hand, in a project consisting of 7 commercial farms, Chebel et al. (2010) detected $48.7 \%$ of cows in estrus after estrus synchronization using visual observation and tail chalk with a range of 26.7 to $59.8 \%$ between farms. Results from the present study showed a discrepancy in the detection of estrus between the 2 farms (65.0 vs. $34.4 \%$ ), demonstrating that not only parity (Fricke et al., 2014b), cyclicity (Chebel and Santos, 2010), and BCS (DeJarnette et al., 2001) influence estrous detection rates, but farm variation is a key player on the efficacy of these programs.

We observed $20.2 \%$ of cows to be anovular by 50 DIM and cyclicity had negative effects on pregnancy outcomes, days to conception, and detection of estrus after the presynchronization protocol, as well as duration and peak intensity of estrus. Cyclicity was also found to have an interaction with treatment for pregnancy per AI as well as days to conception, where cows that were anovulatory and enrolled in the ACT treatment were the most compromised in both reproductive measures. This prevalence of anovular cows is similar to those found in the United States (average 23\% from 50 to 65 DIM; Bamber et al., 2009). The detrimental effects of prolonged anovulation postpartum have been previously reported in the form of lower conception rates at first postpartum AI, increased days to conception (Chebel and Santos, 2010), and increased pregnancy loss (Sterry et al., 2006; Silva et al., 2007). Yániz et al. (2006) described that cows whom had more estrus events from parturition until 50 DIM had greater pregnancy success by 90 DIM.

Results from our study suggest that parity is also a risk factor for poor fertility, as it increases days to conception and reduces pregnancy per AI and estrous expression. Greater parity has previously been reported to affect conception rate (Tenhagen et al., 2004b; Fricke et al., 2014a; Madureira et al., 2015) and increase days to conception (Fricke et al., 2014b). Estrous expression is affected by parity as well, shown in the current study by a decrease in intensity and duration of estrus, and in other studies where a change in walking activity at estrus has been shown to decrease as lactation number increases (Roelofs et al., 2005; Yániz et al., 2006; Madureira et al., 2015). This work is contrary to others that reported parity had no effect on intensity or duration of behaviors at estrus (Veerkamp et al., 2000; Løvendahl and Chagunda, 2010; Valenza et al., 2012). Using similar treatments as the present study, Fricke et al. (2014b) found a parity by treatment interaction, where multiparous and primiparous cows had similar pregnancy per $\mathrm{AI}$ in their equivalent $\mathrm{ACT}$ treatment, whereas multiparous had reduced pregnancy per AI in their equivalent TAI treatment. In the present study, we also found an interaction between parity and treatment, but, contrary to Fricke et al. (2014b), we found that primiparous and multiparous cows had similar pregnancy per AI for the TAI treatment. Primiparous cows had greater odds of pregnancy than multiparous cows when enrolled in the ACT treatment; these results are similar to those found by Stevenson et al. (2014).

The present study, as well as others evaluating the efficacy of AAM, consistently found an interaction between treatment and farm regarding the detection of estrus and pregnancy rates. This adds to the discussion about ideal reproductive programs and strengthens the need for consideration of the specific strengths of each farm (e.g., proper and consistent use of AAM, complying with injection schedules, and so on) during on-farm decision-making regarding reproductive management (Tenhagen et al., 2004a; Stevenson and Phatak, 2005). In an economic model by Giordano et al. (2012) comparing 100\% timed AI reproductive programs with programs that incorporate the use of detection of estrus, the importance of farm-specific reproductive management programs was portrayed. Those authors found that farms with poor pregnancy per AI when inseminating at detected estrus benefited economically by completing timed AI protocols. However, farms that can obtain 30 to $35 \%$ conception rates from inseminations at the time of estrus are always more profitable by submitting their cows to AI at the time of estrus instead of completing the full timed AI protocol. In a different economic assessment, researchers assessed 
reproductive performance and profit using a simulation model of different reproductive programs composed of either detection for estrus, timed AI, or a mix of both methods (Galvão et al., 2013). They concluded that both profit and reproductive performance was maximized when farms combined both the detection of estrus and timed AI protocols into their reproductive management; however, if herds can achieve high service rates with either method, they may be able to achieve greater profits by focusing on just one.

\section{CONCLUSIONS}

This study demonstrated that using AAM for detection of estrus within a Presynch-Ovsynch program resulted in similar pregnancy per AI and days open compared with a reproduction program that was strictly based on timed AI for first AI. It is important to note that there was a significant effect of farm, suggesting that the use of AAM are probably more prone to individual farm variations, particularly when compared with more established timed AI protocols. In addition, this study demonstrated that lameness was indeed a problem on the farm with the greater prevalence of leg health injuries, where it increased the days to conception and decreased the odds of pregnancy, but both leg health and poor BCS had no effect on peak intensity and duration of estrus as measured by AAM.

\section{ACKNOWLEDGMENTS}

This study was supported by a contribution from the Dairy Research Cluster Initiative II (Dairy Farmers of Canada, Agriculture and Agri-Food Canada, the Canadian Dairy Network and the Canadian Dairy Commission, Ontario, Canada). Partial funding was also provided by the Natural Sciences and Engineering Research Council Discovery Grant (Ontario, Canada). The authors also thank Nelson Dinn and all students that assisted with data collection at the UBC's Dairy Education and Research Centre (Agassiz, British Columbia, Canada).

\section{REFERENCES}

Alsaaod, M., C. Römer, J. Kleinmanns, K. Hendriksen, S. Rose-Meierhöfer, L. Plümer, and W. Büscher. 2012. Electronic detection of lameness in dairy cows through measuring pedometric activity and lying behavior. Appl. Anim. Behav. Sci. 142:134-141.

Aungier, S. P. M., J. F. Roche, M. Sheehy, and M. A. Crowe. 2012. Effects of management and health on the use of activity monitoring of estrus detection in dairy cows. J. Dairy Sci. 95:2452-2466.

Bamber, R. L., G. E. Shook, M. C. Wiltbank, J. E. P. Santos, and P. M. Fricke. 2009. Genetic parameters for anovulation and pregnancy loss in dairy cattle. J. Dairy Sci. 92:5739-5753.
Butler, W. R. 2003. Energy balance relationships with follicular development, ovulation and fertility in postpartum dairy cows. Livest. Prod. Sci. 83:211-218.

Canadian Council for Animal Care. 2009. The Care and Use of Farm Animals in Research, Teaching and Testing. Canadian Council for Animal Care, Ottawa, Ontario, Canada.

Caraviello, D. Z., K. A. Weigel, P. M. Fricke, M. C. Wiltbank, M. J. Florent, N. B. Cook, K. V. Nordlund, N. R. Zwald, and C. L. Rawson. 2006. Survey of management practices on reproductive performance of dairy cattle on large US commercial farms. J. Dairy Sci. 89:4723-4735.

Cartmill, J. A., S. Z. El-Zarkouny, B. A. Hensley, T. G. Rozell, J. F. Smith, and J. S. Stevenson. 2001. An alternative AI breeding protocol for dairy cows exposed to elevated ambient temperatures before or after calving or both. J. Dairy Sci. 84:799-806.

Cerri, R. L. A., J. E. P. Santos, S. O. Juchem, K. N. Galvão, and R. C. Chebel. 2004. Timed artificial insemination with estradiol cypionate or insemination at estrus in high-producing dairy cows. J. Dairy Sci. 87:3704-3715.

Chapinal, N., A. M. de Passillé, J. Rushen, and S. Wagnar. 2010. Automated methods for detecting lameness and measuring analgesia in dairy cattle. J. Dairy Sci. 93:2007-2013.

Chebel, R. C., M. J. Al-Hassan, P. M. Fricke, J. E. P. Santos, J. R. Lima, C. A. Martel, J. S. Stevenson, R. Garcia, and R. L. Ax. 2010. Supplementation of progesterone via controlled internal drug release inserts during ovulation synchronization protocols in lactating dairy cows. J. Dairy Sci. 93:922-931.

Chebel, R. C., and J. E. P. Santos. 2010. Effect of inseminating cows in estrus following a presynchronization protocol on reproductive and lactation performances. J. Dairy Sci. 93:4632-4643.

Dalton, J. C., R. Manzo, A. Ahmadzadeh, B. Shafii, W. J. Price, and J. M. DeJarnette. 2005. Short communication: Conception rate following detection of estrus and timed AI in dairy cows synchronized using GnRH and PGF $_{2 \alpha}$. J. Dairy Sci. 88:4313-4316.

de Mol, R. M., G. André, E. J. B. Bleumer, J. T. N. van der Werf, Y. de Haas, and C. G. van Reenen. 2013. Applicability of day-to-day variation in behavior for the automated detection of lameness in dairy cows. J. Dairy Sci. 96:3703-3712.

DeJarnette, J. M., R. R. Salverson, and C. E. Marshall. 2001. Incidence of premature estrus in lactating dairy cows and conception rates to standing estrus or fixed-time inseminations after synchronization using GnRH and PGF2 $\alpha$. Anim. Reprod. Sci. 67:27-35.

Denis-Robichaud, J., R. L. A. Cerri, A. Jones-Bitton, and S. J. LeBlanc. 2016. Survey of reproduction management on Canadian dairy farms. J. Dairy Sci. 99:9338-9351.

Diskin, M. G., and J. M. Sreenan. 2000. Expression and detection of oestrus in cattle. Reprod. Nutr. Dev. 40:481-491.

Dolecheck, K. A., W. J. Silvia, G. Heersche Jr., C. L. Wood, K. J. McQuerry, and J. M. Bewley. 2016. A comparison of timed artificial insemination and automated activity monitoring with hormone intervention in 3 commercial dairy herds. J. Dairy Sci. 99:1506-1514.

Edmonson, A. J., I. J. Lean, L. D. Weaver, T. Farver, and G. Webster. 1989. A body condition scoring chart for Holstein dairy cows. J. Dairy Sci. 72:68-78.

Flower, F. C., and D. M. Weary. 2006. Effect of hoof pathologies on subjective assessments of dairy cow gait. J. Dairy Sci. 89:139-146.

Fricke, P. M., P. D. Carvalho, J. O. Giordano, A. Valenza, G. Lopes Jr., and M. C. Amundson. 2014a. Expression and detection of estrus in dairy cows: The role of new technologies. Animal 8:134-143.

Fricke, P. M., J. O. Giordano, A. Valenza, G. Lopes Jr., M. C. Amundson, and P. D. Carvalho. 2014b. Reproductive performance of lactating dairy cows managed for first service using timed artificial insemination with or without detection of estrus using an activitymonitoring system. J. Dairy Sci. 97:2771-2781.

Galvão, K. N., P. Frederico, A. De Vries, and G. M. Schuenemann. 2013. Economic comparison of reproductive programs for dairy herds using estrus detection, timed artificial insemination, or a combination. J. Dairy Sci. 96:2681-2693.

Giordano, J. O., A. S. Kalantari, P. M. Fricke, M. C. Wiltbank, and V. E. Cabrera. 2012. A daily herd Markov-chain model to study the reproductive and economic impact of reproductive programs 
combining timed artificial insemination and estrous detection. J. Dairy Sci. 95:5442-5460.

Giordano, J. O., M. L. Stangaferro, R. Wijma, W. C. Chandler, and R. D. Watters. 2015. Reproductive performance of dairy cows managed with a program aimed at increasing insemination of cows in estrus based on increased physical activity and fertility of timed artificial inseminations. J. Dairy Sci. 98:2488-2501.

Gümen, A., J. N. Guenther, and M. C. Wiltbank. 2003. Follicular size and response to ovsynch versus detection of estrus in anovular and ovular lactating dairy cows. J. Dairy Sci. 86:3184-3194.

Gumen, A., A. Keskin, G. Yilmazbas-Mecitoglu, E. Karakaya, A. Alkan, H. Okut, and M. C. Wiltbank. 2012. Effect of a presynchronization strategy before Ovsynch on fertility at first service in lactating dairy cows. Theriogenology 78:1830-1838.

Hall, J. G., C. Branton, and E. J. Stone. 1959. Estrus, estrous cycles, ovulation time, time of service and fertility of dairy cattle in Louisiana. J. Dairy Sci. 42:1086-1094.

Hockey, C., J. Morton, S. Norman, and M. McGowan. 2010. Evaluation of a neck mounted 2-hourly activity meter system for detecting cows about to ovulate in two paddock-based Australian dairy herds. Reprod. Domest. Anim. 45:e107-e117.

López-Gatius, F., P. Santolaria, I. Mundet, and J. L. Yániz. 2005. Walking activity at estrus and subsequent fertility in dairy cows. Theriogenology 63:1419-1429.

Løvendahl, P., and G. G. Chagunda. 2010. On the use of physical activity monitoring for estrus detection in dairy cows. J. Dairy Sci. 93:249-259.

Madureira, A. M. L., B. F. Silper, T. A. Burnett, L. Polsky, L. H. Cruppe, D. M. Veira, J. L. M. Vasconcelos, and R. L. A. Cerri. 2015. Factors affecting expression of estrus measured by activity monitors and conception risk of lactating dairy cows. J. Dairy Sci. 98:7003-7014

Neves, R. C., and S. J. LeBlanc. 2015. Reproductive management practices and performance of Canadian dairy herds using automated activity-monitoring systems. J. Dairy Sci. 98:2801-2811.

Neves, R. C., K. E. Leslie, J. S. Walton, and S. J. LeBlanc. 2012. Reproductive performance with an automated activity monitoring system versus a synchronized breeding program. J. Dairy Sci. 95:5683-5693.

NRC. 2001. Nutrient Requirements of Dairy Cattle. 7th rev. ed. Natl. Acad. Sci., Washington, DC.

O'Callaghan, K. A., P. J. Cripps, D. Y. Downham, and R. D. Murray. 2003. Subjective and objective assessment of pain and discomfort due to lameness in dairy cattle. Anim. Welf. 12:605-610.

Pieper, L., M. G. Doherr, and W. Heuwieser. 2016. Consumers' attitudes about milk quality and fertilization methods in dairy cow in Germany. J. Dairy Sci. 99:3162-3170.

Roelofs, J. B., E. G. Bouwman, S. J. Dieleman, F. J. Van Eerdenburg, L. M. Kaal-Lansbergen, N. M. Soede, and B. Kemp. 2004. Influence of repeated rectal ultrasound examinations on hormone profiles and behaviour around oestrus and ovulation in dairy cattle. Theriogenology 62:1337-1352.

Roelofs, J. B., F. López-Gatius, R. H. F. Hunter, F. J. C. M. van Eerdenburg, and Ch. Hanzen. 2010. When is a cow in estrus? Clinical and practical aspects. Theriogenology 74:327-344.

Roelofs, J., F. J. van Eerdenburg, N. M. Soede, and B. Kemp. 2005. Pedometer readings for estrous detection and as predictor for time of ovulation in dairy cattle. Theriogenology 64:1690-1703.
Saint-Dizier, M., and S. Chastant-Maillard. 2012. Towards an automated detection of oestrus in dairy cattle. Reprod. Domest. Anim. 47:1056-1061.

Silva, E., R. A. Sterry, and P. M. Fricke. 2007. Assessment of a practical method for identifying anovular lactating dairy cows synchronized for first postpartum timed artificial insemination. J. Dairy Sci. 90:3255-3262.

Sterry, R. A., M. L. Welle, and P. M. Fricke. 2006. Treatment with gonadotropin-releasing hormone after first timed AI improves fertility in noncycling lactating dairy cows. J. Dairy Sci. 89:4237-4245.

Stevenson, J. S. 2001. Reproductive management of dairy cows in high milk-producing herds. J. Dairy Sci. 84(Suppl.):E128-E143.

Stevenson, J. S., S. L. Hill, R. L. Nebel, and J. M. DeJarnette. 2014 Ovulation timing and conception risk after automated activity monitoring in lactating dairy cows. J. Dairy Sci. 97:4296-4308.

Stevenson, J. S., and A. P. Phatak. 2005. Insemination at estrus induced by presynchronization before application of synchronized estrus and ovulation. J. Dairy Sci. 88:399-405.

Tenhagen, B. A., M. Drillich, R. Surholt, and W. Heuwieser. 2004a. Comparison of timed AI after synchronized ovulation to AI at estrus: Reproductive and economic considerations. J. Dairy Sci. 87:85-94.

Tenhagen, B. A., R. Surholt, M. Wittke, C. Vogel, M. Drillich, and W. Heuwieser. 2004b. Use of Ovsynch in dairy herds: Differences between primiparous and multiparous cows. Anim. Reprod. Sci. 81:1-11.

Tenhagen, B. A., C. Vogel, M. Drillich, G. Thiele, and W. Heuwieser. 2003. Influence of stage of lactation and milk production on conception rates after timed artificial insemination following Ovsynch. Theriogenology 60:1527-1537.

Thorup, V. M., L. Munksgaard, P. E. Robert, H. W. Erhard, P. T Thomsen, and N. C. Friggens. 2015. Lameness detection via legmounted accelerometers on dairy cows on four commercial farms. Animal 9:1704-1712

Valenza, A., J. O. Giordano, G. Lopes Jr., L. Vincenti, M. C. Amundson, and P. M. Fricke. 2012. Assessment of an accelerometer system for detection of estrus and treatment with gonadotropin-releasing hormone at the time of insemination in lactating dairy cows. J. Dairy Sci. 95:7115-7127.

Van Vliet, J. H., and F. J. C. M. Van Eerdenburg. 1996. Sexual activities and oestrus detection in lactating Holstein cows. Appl. Anim. Behav. Sci. 50:57-69.

Veerkamp, R. F., J. K. Oldenbroek, H. J. van der Gaast, and J. H. J. van der Werf. 2000. Genetic correlation between days until start of luteal activity and milk yield, energy balance, and live weights. J. Dairy Sci. 83:577-583.

Walker, S. L., R. F. Smith, D. N. Jones, J. E. Routly, and H. Dobson. 2008. Chronic stress, hormone profiles and estrus intensity in dairy cattle. Horm. Behav. 53:493-501.

Yániz, J. L., P. Santolaria, A. Giribet, and F. López-Gatius. 2006. Factors affecting walking activity at estrus during postpartum period and subsequent fertility in dairy cows. Theriogenology 66:19431950. 